Revista Iberoamericana, Vol. LXXIV, Núm. 223, Abril-Junio 2008, 405-422

\title{
“EN ÁTOMOS VOLANDO”: TRANSFORMACIONES DE LA ICONOGRAFÍA PATRIÓTICA EN LA PRODUCCIÓN CULTURAL CONTEMPORÁNEA COLOMBIANA
}

\author{
POR \\ JuANA SUÁREZ \\ University of Kentucky
}

\begin{abstract}
“En átomos volando” es un verso del himno nacional que describe la muerte de Antonio Ricaurte y sirve aquí como imagen ilustrativa de un proceso similar al que parecería atravesar la iconografía patriótica nacional. Usualmente establecidos por el Estado para representar aquella comunidad imaginada que sería la nación, promover el fervor patriótico y aumentar el sentimiento nacionalista que encontraría en ellos el depósito de una identidad común, estos símbolos (el escudo, la bandera, el himno nacional y la colección de imágenes y retratos de los héroes de las batallas de independencia del siglo XIX) son objeto de múltiples usos y reconversiones en el panorama colombiano actual. El objetivo central de este ensayo será describir y discutir la apropiación y desmantelamiento actual de dicha iconografía que se hace conspicua tanto en el sector estatal como en la cultura popular. De los múltiples ejemplos de producción cultural contemporánea que insisten en el uso de la misma, me interesan aquellos que, al abordar la preocupación por una redefinición, ofrecen una contra-narrativa a la retórica de la nación tal como se invierte en ese capital simbólico.

Es pertinente empezar por algunas anotaciones sobre la preocupación del gobierno actual por la iconografía patriótica para señalar cómo este gesto estatal sólo ha venido a galvanizar un malestar que la nación ya evidenciaba frente a la validez y vigencia de la misma, así como frenteal carácter representativoinherente a colecciones demuseos, estatuas, monumentos y otros componentes del patrimonio nacional. Así mismo, dado que la reconversión de este capital simbólico aparece como una respuesta antagónica al discurso de la violencia en Colombia, se hace preciso puntualizar algunas observaciones actuales en torno a ese tema.

Paralelo al comienzo del primer periodo de gobierno de Álvaro Uribe (7 de agosto de 2002), Colombia ha presenciado un despliegue inusitado de usos del tricolor patrio en todo tipo de bienes de consumo, y el más visible es una pulsera que muchos ciudadanos portan, en particular los sectores juveniles. ${ }^{1}$ El éxito de este artefacto (y para tal efecto, de toda la
\end{abstract}

\footnotetext{
${ }^{1}$ La popularidad de dichas pulseras, que empezaron siendo un artefacto artesanal en telar o cuentas plásticas, se ha extendido hasta el punto de que grandes almacenes de bisutería y joyerías han lanzado al mercado sofisticados diseños echando mano de recursos materiales más caros como el oro, la plata y las piedras preciosas. Además de almacenes, se distribuyen en tiendas como la del Museo de Antioquia y algunas galerías de arte. La propagación de iconografía tricolor se ha extendido a todo tipo de utensilios al mismo tiempo que la referencia a la bandera se ha hecho más reiterativa en el engranaje
} 
parafernalia amarilla, azul y roja) responde a una búsqueda de afiliación nacional como resultado de un proceso de “reconstrucción” de una identidad nacional y, al mismo tiempo, a intentos de recuperación de un orgullo patrio, acechado muchas veces por el estigma del narcotráfico que como una letra escarlata acompaña el desempeño público e internacional de ser ciudadano colombiano. Este despliegue patriótico también tiene mucho que ver con la acogida que algunos de los proyectos uribistas han tenido, en particular la campaña "Vive Colombia, viaja por ella”, una propuesta de recuperación del territorio nacional, encarnada literalmente en las caravanas turísticas que se han popularizado durante este periodo presidencial. Tácticas de violencia como el secuestro, la "vacuna”, las “pescas milagrosas” y el "paseo millonario" puestas en práctica tanto por grupos guerrilleros y paramilitares como por delincuentes comunes han dificultado por varios años la movilización de los colombianos por las diferentes regiones del país, amén del severo impacto que han tenido en el sector turístico. La adjudicación que hiciera el gobierno de Andrés Pastrana de la zona conocida como el Caguán a las FARC-EP, significó para el ciudadano común un sentido de pérdida de dominio y soberanía del territorio nacional por parte del Estado. Los visos populistas del gobierno de Uribe han ofrecido, al parecer, una garantía de recuperación de un mapa transitable, por medio de una suerte de cruzada nacionalista que, como tal, debe valerse de la iconografía patriótica en su intento de demarcar aquellos espacios geográficos donde la presencia del Estado ha sido desestabilizada por las consecuencias del llamado conflicto armado. ${ }^{2}$

Con este trasfondo, no resulta paradójico que el mismo Uribe recientemente convocara a un rediseño del escudo nacional. ${ }^{3}$ La actual preocupación estatal por la articulación del discurso de identidad nacional no se reduce a los emblemas patrióticos sino que se extiende a aquellos objetos, fetiches, artefactos y demás que conforman el patrimonio cultural de la nación. ${ }^{4}$ La invitación de Uribe vigoriza un diálogo existente desde hace varios años entre

publicitario de diferentes productos y servicios, baste mencionar el lema del propio Ministerio de Cultura: "Vive Colombia, siente tu bandera".

${ }^{2}$ Las caravanas turísticas consisten en recorridos masivos que se originan en un punto de encuentro y aglomeran a ciudadanos ansiosos de pasear los fines de semana o periodos vacacionales. Los recorridos se hacen escoltados por las fuerzas del orden, buscando contrarrestar robos y saqueos por parte de grupos guerrilleros y paramilitares así como por grupos de delincuentes comunes. Aunque varían en su implementación, las "vacunas" consisten en cantidades de dinero o propiedades que se logran por medio de la extorsión a quienes tienen fincas o terrenos; las "pescas milagrosas" son asaltos a transporte público y privado y el "paseo millonario" es un secuestro temporal con el fin específico de hacer que la víctima retire la mayor cantidad de dinero posible de su cuenta bancaria con su tarjeta de cajero automático y/o haga el mayor número de compras posibles con su tarjeta de crédito.

${ }^{3}$ La propuesta específica fue encargada al publicista Carlos Duque, asesor de imagen de la campaña presidencial de Uribe, no sin generar bastantes aspavientos dentro del país.

${ }^{4}$ Apenas a comienzos del año 2001 se suscitó una polémica por la plausible exhibición de la toalla roja de Manuel Marulanda Vélez (alias “Tirofijo”) en una colección del Museo Nacional. La sugerencia de Elvira Cuervo, entonces directora del museo, iba en consonancia con la concepción que plantea García Canclini de que esos recintos “como medios masivos de comunicación, pueden desempeñar un papel significativo en la democratización de la cultura y en el cambio de concepto de cultura” (159). Herbert Braun sugiere que la posición de Cuervo era una manera de llamar la atención sobre la falta de memoria histórica del país (2004 xiv). 
artistas y medios que han apelado a la cita posmoderna, la desacralización y la reconversión del capital simbólico patriótico para sentar precedentes y posiciones contestatarias a lo que García Canclini denomina "tradicionalismo sustancialista” (150). Precisamente, diversas manifestaciones culturales surgen como desafío al carácter de "don” y de "prestigio social” que, subraya el crítico, se confiere a ese "conjunto de bienes y prácticas tradicionales que nos identifican como nación” (150) y que nos hace pensar que la única posibilidad sería "preservarlo, reservarlo, difundirlo" (150). Si bien esta tendencia artística no es reciente, se posiciona actualmente en un país que, bajo el ala de Uribe, intenta restaurar la credibilidad de sus dispositivos estatales, particularmente frente al gobierno de Estados Unidos, en un momento en el que se han activado las cartas de participación del país en el Tratado de Libre Comercio. Puesto así, el uso de capital simbólico patriótico en diferentes manifestaciones artísticas y culturales, que no son convocadas ni avaladas por el Estado, sugiere el trazo de otras coordenadas respecto al discurso oficial sobre la violencia y cómo se entiende el sentido de pertenencia, lealtad y protección invertido en los iconos nacionales y el patrimonio cultural.

Algunas de las dimensiones de esta compulsión patriótica hacen eco del proyecto de construcción de identidad nacional en el siglo xIx en América Latina, particularmente el papel que jugó el capital simbólico en la creación de comunidades imaginadas y configuración de la nación. La susceptibilidad de renovación de la heráldica nacional, la manera como iconografía y patrimonio pueden enarbolar el performance político de turno y la presencia desestabilizadora de la misma en productos culturales contradicen aseveraciones sobre la “consolidación” de la nación, dejando al descubierto las llagas resultantes del conflicto entre un pasado y un presente no resueltos en la Colombia de los tiempos del neoliberalismo. Reconocidos artistas (Maripaz Jaramillo, Santiago Cárdenas y Antonio Caro, entre otros) tomaron la convocatoria como excusa para desarrollar visualmente ideas sobre los elementos que representarían la nación y la correspondencia entre el sujeto nacional y los significados que el escudo cobraría en la Colombia actual. Aunque algunas no coincidan con el carácter ceremonioso que el Estado ha conferido a la convocatoria, a estas respuestas las alienta la misma preocupación del discurso articulado por el Estado sobre lo perteneciente y no perteneciente a la nación, lo que es y no es colombiano. A otro nivel, algunas de las respuestas -a diferencia de la propuesta- tienen en cuenta un discurso articulado por el sujeto, resultado de intercambios cotidianos y de respuestas concretas a la contraria perplejidad del caos nacional. En esas articulaciones, lo performativo se aleja de lo pedagógico dando paso a lo que Homi Bhabha argumenta ser evidencia de que el pueblo "no sólo se compone de eventos históricos o partes de un cuerpo patriótico sino que es también una compleja estrategia retórica de referencia social en estrecha relación con los principios vivos del pueblo como contemporaneidad; es decir, con el proceso continuo por medio del cual la vida nacional se redime y cobra significado como un proceso reproductivo" (297, mi traducción).

Puesto así, las partes del escudo estarían más en sintonía con la forma irónica como la ciudadanía colombiana ha aprendido a referirse a su patria como "el país del Divino Niño”, "el surco de dolores” o responder a las tragedias y calamidades nacionales con el " $\mathrm{OOh}$ gloria inmarcesible!” que abre el himno nacional. Al fin y al cabo, este tipo de elementos corresponde a prácticas discursivas y significados que, como lo propone Stuart Hall, articulan las identidades culturales no como prácticas fijas y esencializadas en el pasado, sino como resultado del 
incesante juego entre historia, cultura y poder que acompaña el discurso público, convirtiendo las identidades en equivalentes a los diversos modos por los que somos posicionados y nos posicionamos dentro de las narrativas del pasado (225).

Con trazos más modernos y dinámicos que se oponen a la rigidez del escudo original, muchos de estos artistas han substituido elementos como el cóndor y el gorro frigio. Otros han incluido la imagen del Divino Niño (que en el imaginario popular ha venido a continuar la antigua devoción estatal al Sagrado Corazón de Jesús) y objetos que remiten al consumo. Por ejemplo, a la propuesta de Iván Onatra la preside la imagen de Cervecería Águila; además contiene etiquetas de la chocolatina Jet y la imagen de cigarrillos pielroja en lugar de las imágenes de la cornucopia y del gorro frigio (Baena 25; ilustración \#1). La propuesta

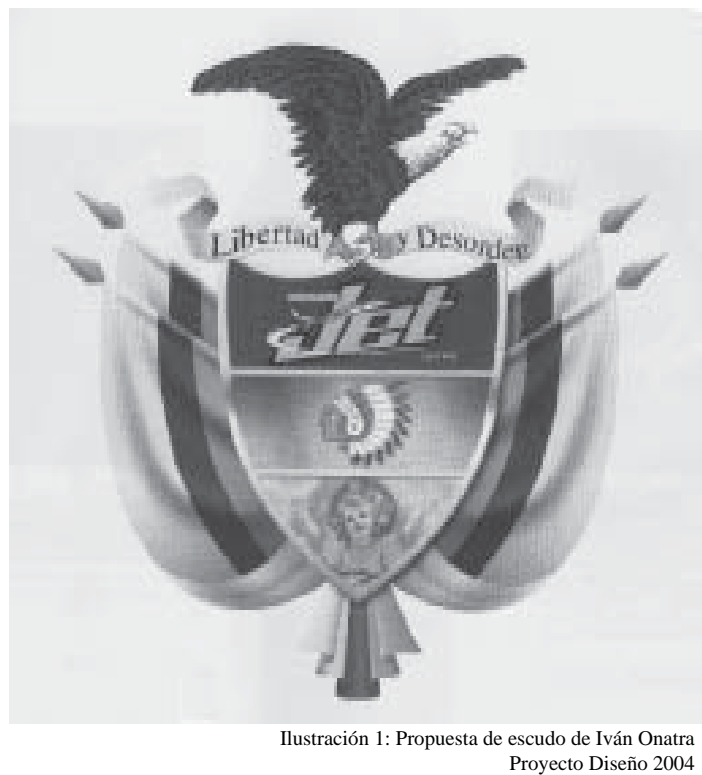

de Patricia Durán coincide en el águila en lugar del cóndor y está elaborada sobre una tapa de Coca-Cola pues, según la artista, dicha bebida "es un símbolo tan reconocible para los colombianos como el mismo Escudo Nacional” (Baena 27; ilustración \#2).

Bernardo Salcedo exhibió nuevamente una propuesta que ya había hecho en 1970, en la cual negaba radicalmente "la abundancia”, "la libertad” "el escudo” y "la patria” (Baena 22-28; ilustración \#3). ${ }^{5}$ Los rediseños propuestos en torno al escudo nacional ameritarían un

${ }^{5}$ Tanto el artículo mencionado de la Revista Credencial como el de Cambio ilustran gráficamente las propuestas artísticamente recibidas. Revista Credencial presenta los escudos exhibidos en Galería La Cometa de Bogotá con ocasión de la convocatoria. Cambio ofrece un resumen de trabajos reseñados en la revista Proyectodiseño que también había convocado a modificar el escudo. El artículo ilustra otro tipo de trabajos artísticos en torno a la iconografía nacional. 


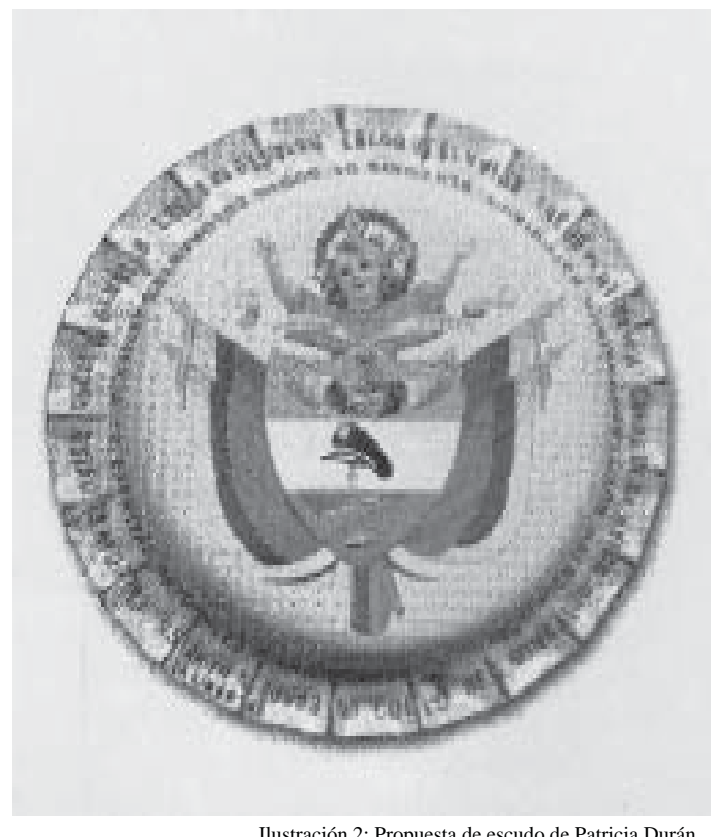

Ilustración 2: Propuesta de escudo de Patricia Durán

estudio particular tanto de sus características estéticas como de las motivaciones políticas que las avalan pero no será de ellas que me ocupe aquí. Más que una lectura minuciosa, exhaustiva e individual de diferentes productos culturales, me propongo reseñar cómo ciertos sectores de la escena cultural colombiana han venido adelantado un diálogo tácito sobre los límites de la iconografía nacional para negociar mecanismos de inclusión y exclusión en relación a la inscripción de la ciudadanía, teniendo en cuenta el orden actual en Colombia y su relación con las diversas formas de violencia que confluyen en el país. Me interesa discutir cómo la iconografía nacional aparece incluida, y con qué fin, en algunos ejemplos musicales, medios de comunicación, manifestaciones de humor y películas. Igualmente, la inquietud por reinventar los símbolos patrios que se manifiesta tanto en los sectores oficiales del Estado como en la producción cultural tiene mucho que decir sobre los diversos matices que cobran en el discurso de la nación colombiana, los diálogos y disensiones sobre la pluralidad y la diversidad y, especialmente, sobre las varias maneras como la cultura (re)presenta la nación. Señalé previamente que la incorporación de la iconografía patriótica y patrimonio cultural nacional en el arte colombiano no es reciente. Ya desde la década de los 70 se evidenciaba una fuerte tendencia a utilizar la iconografía patriótica como cita posmoderna que permitía la ironía. ${ }^{6}$ Es la reconfiguración de un orden político al margen del Estado, específicamente aquel exacerbado por la presencia de fenómenos como el narcotráfico, el paramilitarismo y

${ }^{6}$ Para el propósito particular de esta discusión, se han escogido productos culturales posteriores a 1990. Cabe anotar que el uso de iconografía nacionalista que entra en conversación directa con la violencia 


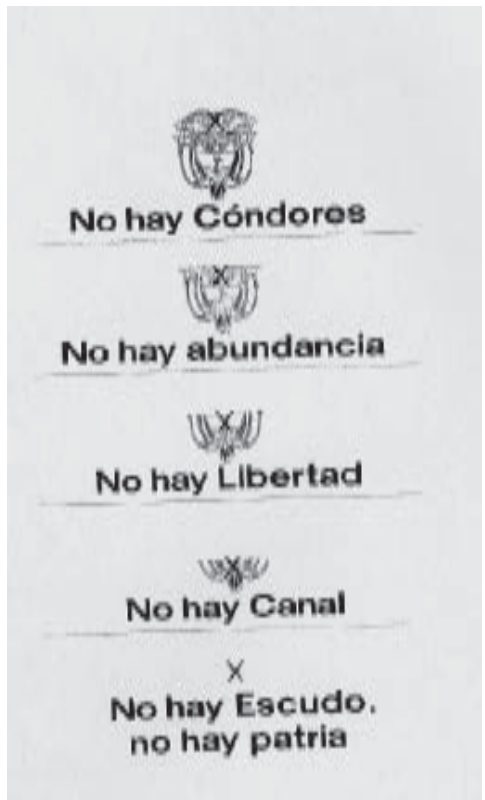

Ilustración 3: Propuesta de escudo de Bernardo Salcedo. Bogotá: Museo de Arte Moderno, 1970.

la guerrilla, la que promueve en los últimos veinte años una insistencia en el desmantelamiento de los símbolos patrios. Una característica sobresaliente de los ejemplos que se ofrecerán posteriormente radica en la deshomogeneización del concepto de violencia en Colombia. A propósito, es pertinente resumir brevemente cuáles son los vértices rectores que conforman dicho discurso. La distancia generacional y la impotencia ha aglutinado un fenómeno diverso bajo ese término uniforme y poco reflexionamos respecto a la diferencia de percepción de diversos referentes históricos para alguien que nació en los años 80 y no ha conocido un país sin narcotráfico, o para alguien que nació en 1950 y no recuerda un país sin luchas guerrilleras y sin narcotráfico, por ejemplo.

En Colombia coexisten la violencia política y la violencia generada por la delincuencia común; tanto la una como la otra repiten frecuentemente anomalías históricas anteriores. La confluencia de estas formas de violencia conjuga las consecuencias de un pasado y un presente no resueltos (una "modernidad postergada" como lo propone el sociólogo colombiano Rubén Jaramillo Vélez) ${ }^{7}$ con una serie de regionalismos -que sobrepasan el fuertemente galvanizado por la narrativa garciamarquina como una contienda entre “cachacos” y “costeños”, frente a las exigencias del neoliberalismo y la manera disruptiva como el narcotráfico ha ubicado a Colombia en la esfera mundial.

se ratifica en Colombia de modo particular en la década del 50, teniendo como preámbulo el trabajo de Débora Arango y Pedro Nel Gómez. Arte y violencia en Colombia desde 1948 ofrece una amplia referencia al respecto. La desmitificación de los iconos nacionales ha sido un motivo recurrente incluso en figuras canónicas del arte nacional como Beatriz González y Fernando Botero.

${ }^{7}$ Aunque es una discusión mucho más amplia, para Jaramillo Vélez, la herencia de la Constitución de 1886 y el periodo de Regeneración abanderado por Rafael Núñez obliteraron el auge intelectual y científico que el país tuviera entre 1860 y 1880 . No sólo el Concordato privilegió nuevamente el epicentro del clero que perpetuó la tradición de la hacienda sino que la gestión de Miguel Antonio Caro significó un regreso a la tradición hispanista. Ni Caro ni sus contemporáneos consideraron los ideales del mundo anglosajón tales como "el progreso industrial, ni las ciencias, ni el liberalismo económico, ni la sociedad individualista, ni el positivismo, ni el método de las ciencias naturales en el campo de las ciencias del espíritu” (48). No sorprende entonces que no encontraban una razón para censurar que España, en su idea de civilización, no hubiera traído consigo "la industria y la técnica, la economía de mercado libre, el estado neutral en materias religiosas, las libertades políticas individuales, sobre todo las libertades económicas, la libertad de prensa y el sufragio universal” (48). Entre las múltiples consecuencias de lo anterior encontramos el peculiar sincretismo de lo moderno y lo premoderno que caracteriza la vida pública en Colombia. 
Colombia es un país definido por una larga historia de corrupción estatal; por ser el país de los grandes carteles de la droga, los paramilitares y los diversos grupos guerrilleros; también el lugar donde suceden a diario eventos inauditos y asesinatos cargados de sevicia. Por estas razones, en Colombia no puede hablarse de violencia como un término unívoco sino más bien de diversas formas de violencia. Una aclaración es pertinente: es bien sabido que en la historia colombiana, la frase La Violencia se refiere a un periodo de violencia comunal que siguió al Bogotazo, disturbios citadinos ocasionados por el asesinato de Jorge Eliécer Gaitán el 9 de abril de 1948. A lo largo del territorio nacional y hasta los años 60, La Violencia se manifestó como una serie de eventos sectarios que dejaron en el imaginario nacional, además de drásticas consecuencias económicas, un listado de bandoleros, guerrilleros y gamonales que buscaban defender sus territorios, uno de ellos Manuel Marulanda Vélez, alias “Tirofijo”, el actual Comandante General de las Fuerzas Armadas Revolucionarias de Colombia (FARC-EP) y además el guerrillero más viejo de América Latina. Colombia entró en el nuevo milenio sin superar una larga cadena de rencillas regionales y sociales, al punto de que aún se discute si se trata de una larga guerra civil no declarada o si se trata de "una guerra contra la sociedad”, propuesta acuñada por el sociólogo francés Daniel Pécaut (en un libro intitulado de igual forma, Guerra contra la sociedad) y que -como él admite- ha tenido gran resonancia tanto a nivel estatal como en el discurso crítico en torno al caso colombiano. Para Pécaut, a pesar de los síntomas y similitudes del conflicto armado, el debilitamiento del Estado en Colombia no ha sido equivalente a su hundimiento total, denominador común en el balance de otras guerras civiles. A lo largo de su discusión, Pécaut retoma eventos históricos de incidencia en el orden actual pero sin una obsesión por encontrar el punto de origen del conflicto en Colombia pues su propósito es mostrar episodios iterativos donde la actitud de la población frente a los actores armados y viceversa constituye esa guerra contra la sociedad.

Algunas discusiones contemporáneas sobre la violencia en Colombia dan prioridad al término "violencias” para enfatizar lo que Cristina Rojas resume como las diversas y cambiantes formas de violencia, caracterizadas por su "multivariedad" y sus diferentes dimensiones según aparecen relacionadas con factores socioeconómicos, políticos, culturales, regionales y -recientemente- con el tráfico de drogas. ${ }^{8}$ Si bien la bibliografía sobre La Violencia en Colombia es abundante, poco se ha escrito sobre las representaciones contemporáneas de las formas de violencia en el país a pesar de la reiterativa presencia del tema en la producción visual, literaria y musical. Precisamente, la vigencia de los estudios

\footnotetext{
${ }^{8}$ La autora recuerda que la Comisión de Estudios sobre la Violencia en Colombia ha hecho una clasificación de, por lo menos, diez tipos diferentes de violencia: la violencia criminal entre el estado y los ciudadanos; la violencia de la guerrilla contra el estado y los ciudadanos; la violencia del Estado contra las guerrillas, los movimientos sociales y las minorías étnicas; la violencia privada no-organizada; la violencia privada organizada y la violencia privada de la familia (xxiii). Es importante anotar que el reporte de dicha Comisión no dejó de ser polémico pues, como señalan autores como Eduardo Posada Carbó, las estadísticas que se manejaron en ese reporte intentaban distraer la responsabilidad del Estado en la resolución del problema de la violencia y su competencia para garantizar el orden. Las cifras buscaban apoyar el diagnóstico de "violencia generalizada" responsabilizando un mayor número de crímenes y homicidios en actos cotidianos de violencia y adjudicando un porcentaje de entre $15 \%$ y $20 \%$ a las fuerzas subversivas (28).
} 
sobre este periodo enfatiza que muchos de los acontecimientos colombianos de los últimos años no pueden entenderse aisladamente de la complejidad de algunos de los eventos de La Violencia que inciden dentro de los fueros de las formas de violencia contemporánea en Colombia. Ingrid Bolívar advierte la necesidad de "cambiar nuestros hábitos de pensar sobre La Violencia" y recuerda que ésta "se vivió en forma diferente en cada zona del país", incluso observando que en algunos departamentos se le llamó “violencia”, en otros “guerra” y en otros se entendió como “revolución”. En la misma línea, Herbert Braun propone una lectura de la violencia "desde abajo", superando maniqueísmos preestablecidos y considerándola no simplemente como "el resultado de las manipulaciones ejercidas por los de arriba" sino también entendiendo cómo se "envolvía a campesinos pasivos, humildes y embrutecidos en sus múltiples proyectos económicos y políticos” (“Cóndores...” 16).

A estos factores se adiciona la manera como se asume el regionalismo y la separación de clases sociales en Colombia. Junto a divisiones entre comunidades pequeñas y cerradas donde los agravios y las rivalidades por tierras han pasado de generación a generación en forma de riña política, el regionalismo es otra característica de la relación del sujeto colombiano y el territorio. La nación no puede concebirse -propone Bhabha con Foucault en mente-como un estado de equilibrio entre diferentes elementos coordinados por una ley justa(301). El marcado carácter de "lo paisa”, “lo bogotano”, "lo valluno”, lo “costeño” entra en contradicción con el postulado de Benedict Anderson sobre una supuesta "camaradería horizontal y profunda que conlleva siempre a la concepción de la nación como una comunidad imaginada”, basada en una fraternidad que primaría por encima de la inigualdad y la exploración (7, mi traducción). A la fragmentación que dicha hostilidad sugiere, se añade la coincidencia en la observación de varios críticos sobre el impacto del ensimismamiento particular de la cultura colombiana -debido principalmente a la inversión política y cultural que favoreció a Bogotá sobre otras ciudades e, igualmente, a la falta de incorporación de otras inmigraciones en el país- y a la incidencia que esto ha tenido en las manifestaciones de violencias regionales y en la inhabilidad del sujeto colombiano para reconocer la alteridad. Herbert Braun añade otra oportuna anotación sobre el ensimismamiento: su relación con la misma geografía e infraestructura del país (“Colombia...” xii). Para críticos como MartínBarbero, esas formas de ensimismado aislamiento siguen operantes en Colombia a pesar de la peculiar manera como el narcotráfico ha situado al país en la escena mundial y en la economía global (“Políticas...” 7). También se suma la discusión sobre la ratificación del poder en Colombia a los mismos partidos políticos institucionalizados en el siglo xIx y el afianzamiento de los mecanismos de administración en los pilares de ese siglo a pesar de las reformas a la Constitución efectuadas en 1991. Las discusiones más recientes sobre en qué medida la Constitución Nacional es incluyente o excluyente del "sujeto nacional” y del "sujeto popular", así como de la aplicabilidad de dicho documento a la convulsionada Colombia contemporánea, señalan principalmente la ausencia de un relato nacional que incluya al ciudadano común y arrojan un balance de la necesidad imperante de diseñar políticas culturales en relación a los diversos anclajes nacionales (3-18). ${ }^{9}$

${ }^{9} \mathrm{El}$ impacto de la ausencia de inmigraciones a Colombia es discutido por William Ospina en ¿Dónde está la franja amarilla? Es, además, una constante temática en las reflexiones de Jesús MartínBarbero. Respecto al artículo sobre "Políticas culturales" de este autor, al citar todas las páginas 
Cabe anotar que fue solo hasta la redacción de la nueva Constitución en 1991 cuando muchas de las minorías étnicas del país fueron reconocidas. Entre documento y praxis, entre texto y realidad, persiste un distanciamiento que sigue siendo una razón prevalente para la violencia social (Bejarano 68-71). Grandes regiones de Colombia y grandes sectores de la población, prominentemente las etnias indígenas y los grupos de origen africano, han sido abandonados e ignorados históricamente por el Estado. Su incorporación en el escenario nacional, y la poca visibilidad que han cobrado, se ha originado al hacerse víctimas o partícipes de cualquiera de las formas de violencia operantes en el país. Basta ilustrarlo con el caso de Arauca, Caquetá, Casanare y Putumayo, denominadas “intendencias” y “comisarías” hasta la Constitución de 1991 por su subordinación económica a los departamentos. Esta masa geográfica que se mencionaba homogéneamente como “Territorios Nacionales” se ubicó en el mapa político del país como departamentos gracias a ese documento. No obstante, la verdadera ubicación en el mapa real del país ha sido consecuencia de cómo el narcotráfico los convirtió en los principales lugares de producción de hoja de coca, amapola, escondites de laboratorios clandestinos de producción de cocaína y cómo se tornaron en lugar de asentamiento tanto de grupos guerrilleros como de autodefensa.

Con esta auscultación de las formas de violencia operantes en Colombia, pasemos a examinar los ejemplos de producción cultural anunciados. Junto al censo y al museo, Anderson clasifica el mapa como una de las instituciones que moldearon la forma en que el estado colonial imaginó su dominio, incluyendo la naturaleza de los seres humanos gobernados, la geografía y la legitimidad del linaje (165-66). La adjudicación del Estado de zonas específicas del país a los llamados “actores del conflicto armado” bajo el pretexto de negociación y despeje (el caso del Caguán mencionado previamente y recientemente la zona de El Rialito, asignada por Uribe para negociaciones con los paramilitares) desafía la soberanía que Anderson argumenta y la supuesta consolidación de territorio que el mapa debería proyectar. Esta distribución del territorio nacional pone en jaque el mapa político del país, produciendo el efecto de una nación que se desintegra y de un Estado que pierde la soberanía frente al dominio del territorio. Durante el gobierno de Andrés Pastrana, la discordia entre los grupos guerrilleros, la instauración de leyes particulares de los grupos guerrilleros en las zonas bajo su control y el antagonismo de los mismos con el gobierno hacía pensar a los colombianos que la división política del país podría cambiar y dar paso a tres naciones diferentes: la República de Colombia, la República del Caguán y la República del Magdalena Medio. El Ocio, un periódico de circulación virtual que se originaba en Medellín y que se caracterizaba por la naturaleza frontal de sus secciones, publicó en su edición del 17 de febrero de 2000, lo que sería entonces el nuevo mapa de Colombia si dicha fragmentación sucediera (Ilustración \#4).

En otra edición se proponía una nueva versión de la bandera colombiana. En lugar del orden tricolor amarillo, azul y rojo, en la propuesta de El Ocio predominaba el rojo en la parte superior mientras que los otros dos colores eran extremadamente angostos (Ilustración \#5). En la iconografía de la bandera colombiana, los colores oficiales designan,

intento modestamente resumir (no reducir) un artículo extenso sobre las incidencias de la violencia en la cultura colombiana y rico en propuestas culturales sobre identidad y diversidad frente al impacto de la globalización. 


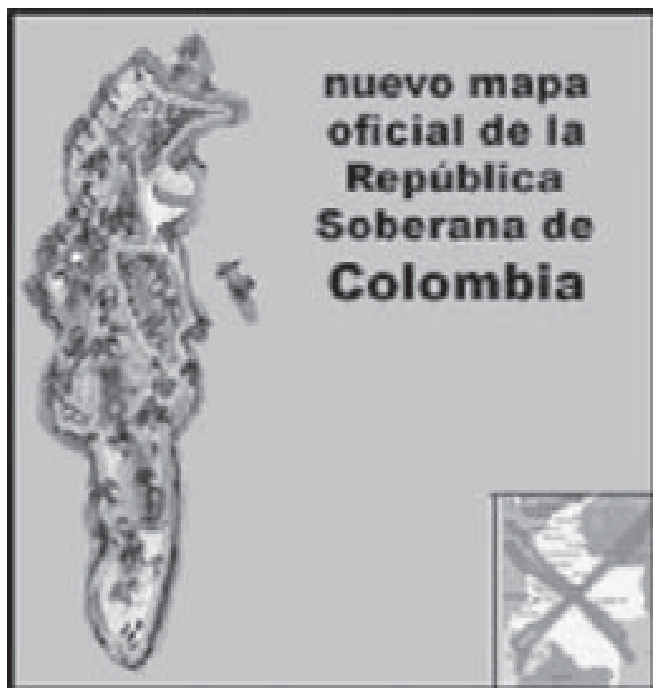

Ilustración 4: Nuevo mapa oficial de la República de Soberana de Colombia presentada por el periódico El Ocio (Medellín: http://www.elocio.com, 2000)

sinestésicamente y en su orden, la riqueza nacional, el azul de los mares y la sangre de los héroes de la Independencia. Por lo menos, con esta retahíla se indoctrina el patriotismo en la escuela, ese recinto que nos recuerda Canclini es "un escenario clave para la teatralización del patrimonio” (154). El proponer una bandera en la que predomina el color rojo constituía una crítica obvia a la violenta situación del país y desvirtuaba la oficialidad tradicional del símbolo patrio. "Mapas-O-Cultos”, instalación de Andrea Echeverri -artista plástica y líder de la banda de rock en español Aterciopelados- figuraba en la página Web de la agrupación hacia el mismo tiempo (Ilustración \#6). Allí se reconstruía el mapa de Colombia

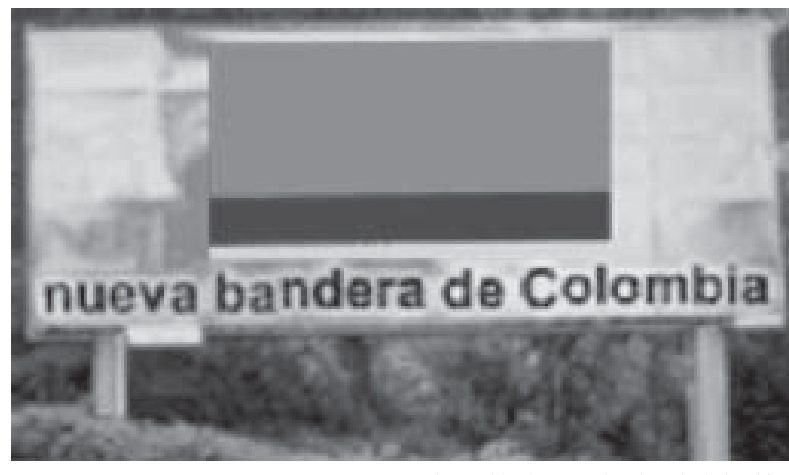

Ilustración 5: Nueva bandera de Colombia Periódico El Ocio (Medellín: http://www.elocio.com 2000) 


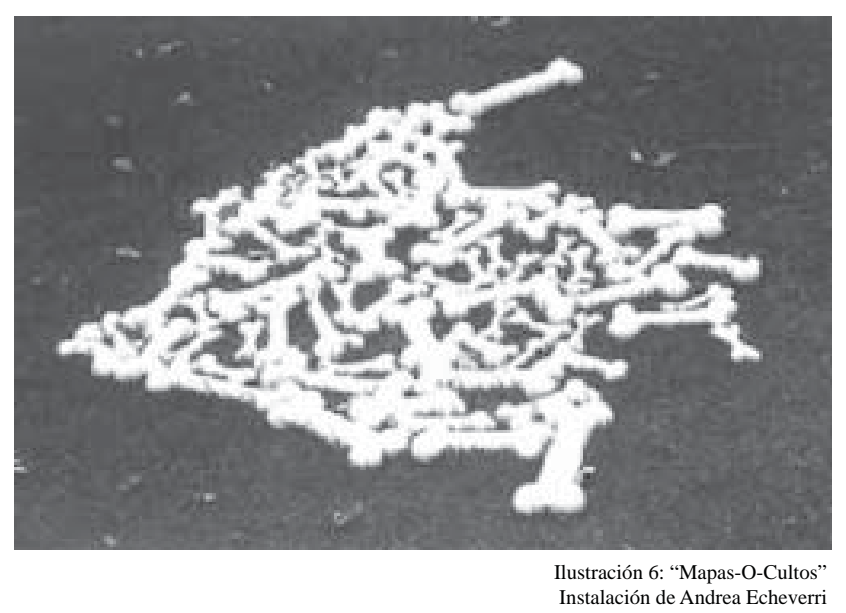

con huesos. El juego de palabras en el título de la obra abría espacio para reflexionar si existe, o quizás se ha creado, un culto a la muerte a partir de la violencia o si, mejor, el mapa oculto de Colombia es el de la muerte.

Las canciones de la banda no se alejaban de la misma temática. El rock en español, junto al rap y al hip-hop son géneros musicales que -tanto en Colombia como en toda América Latina- han tenido una producción masiva y han surgido como ejemplo de transculturación, resultado de la mezcla del rock inglés y estadounidense con diferentes tipos de música latinoamericana, sea en su forma original o en versiones ya transformadas. La evolución de estos géneros de música sucede en gran medida en forma paralela al proceso de incorporación de las ciudades latinoamericanas en un orden global. La ambivalencia natural de estas formas musicales comparte, por un lado, aspectos de la cultura dominante al mismo tiempo que ejerce resistencia a la misma, constituyéndose como un sitio de contienda a los aparatos ideológicos del Estado y a las hegemonías culturales. Una de las estrategias favorecidas es el énfasis en la naturaleza híbrida de las culturas latinoamericanas por medio de una incorporación del pasado y no de una negación o un rechazo. ${ }^{10}$

El disco compacto Evolución (2002) resume la trayectoria de Aterciopelados desde sus incursiones por el punk y el metal de la última parte de la década de los años 80 , hasta derivar en fusiones musicales más new age en los últimos tres años. Esta antología también

\footnotetext{
${ }^{10} \mathrm{Al}$ acelerado ritmo con que la música colombiana parece evidenciar fenómenos de hibridez cultural se contrapone la copiosa producción musical resultante de la exploración histórica y etnográfica de la herencia africana en los dos litorales. La nación presencia un poderoso y ecléctico movimiento musical que intenta dar otra imagen del país a lo largo y ancho del globo terráqueo (una que contrarreste -por medio del éxito de sus artistas- la imagen negativa cultivada por las diferentes formas de violencia, la corrupción y el narcotráfico). Este proceso aparece desafiado por la manera como el engranaje global (mediado en Colombia por la intervención de monopolios musicales estadounidenses) determina lo que musicalmente puede ser reapropiado y transculturado, invitando a una nueva lectura de lo "auténticamente colombiano".
} 
pone de presente cómo Colombia ha sido un referente constante en la poética del grupo así como en conciertos, entrevistas y en los artículos que al respecto se han escrito. Son algunas canciones de El Dorado (1995) y La pipa de la paz (1996) las que critican ampliamente la caída de los iconos nacionales; cuestionan la fuerte alianza entre la iglesia y el estado que funciona como reguladora de la moral; y expresan inquietudes sobre la tolerancia y el entendimiento mutuo por medio de la creación de una cartografía musical para una nación rota, más allá del croquis que abarca ritmos de diferentes rincones colombianos.

En la producción de Aterciopelados hay una exploración de ritmos, imágenes y paisajes de diferentes zonas colombianas. La geografía aparece fragmentada para subrayar la exclusión social como una de las causas primordiales para los diferentes tipos de violencia que coexisten en el país. Dos canciones específicas ilustrarán la manera como Aterciopelados inserta directamente su posición crítica en cuanto a la discusión de lo "nacional” y satiriza la visión neoliberal de la inversión turística en América Latina. "Colombia conexión" empieza con la interrupción abrupta del famoso coro “¡Ay qué orgulloso me siento!” del bambuco nacionalista titulado "Soy colombiano" para inmediatamente ofrecer una versión abreviada de la geografía e historia del país que resume lugares, fechas, personajes históricos, incluyendo el problema del narcotráfico y las rivalidades políticas con los Estados Unidos. Después de ese crescendo, la canción gira a un ritmo lento, reminiscente de la cumbia que, junto al vallenato, se han convertido irónicamente en el epítome internacional para la gran diversidad y riqueza de los ritmos colombianos. Ese cambio paradójico de ritmos sirve en la canción para desmantelar un engañoso orgullo patrio que reduce la nación a "Pobre Colombia irredenta/ desnuda, fría y hambrienta/ a diario tan descontenta/ con la crisis turbulenta” y valiéndose del verso “el bien germina ya”, prestado del himno nacional, produce un efecto contrario al carácter inmediato de la "germinación del bien”, léase fin del conflicto armado. Hugo Chaparro Valderrama identifica la inserción de este verso como una ironía que recuerda la "galería de fantasmas y terrores” de la nación. La lista que le precede señala la insistencia del rock por no limitar el "monocultivo cultural”. Así, "la receta patriótica: el café, el petróleo, el Golfo de Urabá, Aracataca, el bambuco, el torbellino, la Virgen del Carmen, el Cartel, Jorge Eliécer Gaitán, Luis Carlos Galán, Rojas Pinilla...” ofrecida por la canción permite enaltecer el sentimiento patriótico al mismo tiempo que confunde "la perspectiva múltiple de un país que se consuela con los hijos pródigos capaces de sacar la cara por nosotros y nuestras calamidades colombianas" (108).

En “Expreso Amazonía”, la región del Amazonas se toma como locus para establecer una parodia con aquellos paquetes turísticos que comercializan lugares remotos en América Latina. En esta mímica de publicidad que crea la canción, la ironía funciona como recordatorio del lenguaje de las crónicas de Indias y de su invitación a conquistar, colonizar y desafiar la naturaleza. La misma sexualización de la geografía a la que apelan las estrategias publicitarias para vender el espacio o las promociones vacacionales es usada aquí: el Amazonas es presentado como un cuerpo femenino que puede ser explorado y explotado. La posibilidad de coquetear con una mujer nativa (“cuádrese una guerrera

\footnotetext{
${ }^{11}$ Se han tomado solo dos canciones. Siervo sin tierra (a tono con la novela de Eduardo Caballero), Errantes, El Dorado, La pipa de la paz y La voz de la patria complementarían la discusión aquí propuesta y encontraría, eco fácilmente en otras fronteras latinoamericanas.
} 
amazona”), de disfrutar libremente de la excitación sexual (“mójese la canoa”, un verso además interesante porque dialoga con un popular vallenato homofóbico), de hacerse virgen nuevamente y de “desenjaular” el instinto animal son imágenes fuertemente sexualizadas del terreno que invitan a la colonización y que recuerdan la manera como las fantasías sexuales inauguraron América ante los ojos de los europeos. Aquí son recontextualizadas para seducir al turista nacional y extranjero. Beatriz González-Stephan señala que reconvertir "mediante operaciones complejas de simbolización pedazos de la realidad rural como fragmentos del pasado en una modernidad urbana, sostenida básicamente en la cultural de la imagen y del exceso, fue una de las tareas más conspicuas del cuerpo de letrados al servicio del aparato estatal”. Se buscaba que "la nación así maquillada” ofreciera un "espacio para el mercado” (16). Como si repitiéramos un fenómeno del siglo xix pero actualmente frente a otro proceso económico, “Expreso Amazonia” reconvierte la noción del Amazonas como un espacio factible para la inversión turística neoliberal. Tal como fueran los móviles de finales del 1800: "el país debía hacerse atractivo a las inversiones extranjeras y a la inmigración, y de momento, estaba dando muestras de poder brindar condiciones propicias para los no hispanoamericanos" (González-Stephan 17).

Recurrir de esta forma a los emblemas nacionales como el mapa, el himno nacional, el compendio de música nacionalista y situar las canciones en el territorio nacional no es necesariamente iconoclástico ni exclusivo de Aterciopelados. Entre la página web, la estética kitsch de los cuadernillos de los discos compactos y la letra de las canciones, Aterciopelados crea una confluencia de temas y épocas y una crítica irreverente contra las instituciones conservadoras, religiosas y patriarcales. Echeverri resume así la motivación artística del grupo: "El bolero, la salsa, la ranchera, el tango, la estética de los buses, los dichos, el cristianismo, el esoterismo, la violencia, la injusticia, el melodrama, el romanticismo; todo eso se funde en nuestro trabajo como ingredientes extraídos del país donde nacimos y seguimos creciendo” (119). Agrupaciones como Hotel Regina y La Orquesta Sinfónica de Chapinero, liderada por Karl Troller y Eduardo Arias, proponen inversiones similares pero apuntando al patrimonio cultural y a su relación con el espacio urbano y la memoria histórica del país. La carátula de ¡Gaitanista! traspone un collage de ex presidentes de la nación mezclados con figuras de la cultura popular como el Dr. Clímaco Urrutia (un personaje de una serie de televisión humorística que encarnaba al hombrecillo de clase media, clientelista y eterno aspirante a político), Pablo Escobar y Carlos Ledher (narcotraficantes), el "Pibe" Valderrama, Lucho Herrera y René Higuita (glorias deportivas nacionales) y un guerrillero encapuchado del antiguo movimiento M-19, entre otros. ${ }^{12}$ El primer plano lo ocupan los músicos. Todo el conjunto emula la acumulación y distribución en galerías y pabellones propia del museo. Las letras de las canciones son extensiones de lo mismo pero dispuestas en forma de pastiche. Este gesto posmoderno convoca textos literarios, frases y extractos de discursos políticos colombianos y extranjeros y de triunfos de deportistas colombianos. Ilustrado con fotos de El bogotazo, la idea central tanto en la parte sonora como la visual es la "Revolución del 9 de abril". Alrededor de esta fecha se disponen retazos históricos de la nación que desmuseizan el carácter estático de la historiografía nacional. La inclusión de registros sonoros (reales o remedos) con la voz de Jorge Eliécer Gaitán, Darío Echandía,

\footnotetext{
${ }^{12}$ Le agradezco a Gilberto Gómez por facilitarme el material de ;Gaitanista!
} 
Gabriel García Márquez, Luz Marina Zuluaga, locutores deportivos y otros, imprime vitalidad a imágenes que, de otro modo, aparecen como retratos y fotografías inmóviles y adjudican una dimensión corporal y sonora a esas imágenes, haciéndoles cobrar vida. Al yuxtaponer imagen, sonido, cultura alta, cultura popular, lo nacional y lo foráneo, la agrupación desorganiza las galerías del patrimonio nacional y contradice la manera como la imagen se presenta en el catálogo histórico y turístico como "una continuidad sin conflictos entre tradición y modernidad” (García Canclini 184). ${ }^{13}$

El elemento urbano es otra variante temática abordada en este disco compacto. GonzálezStephan subraya el papel decisivo que jugaron formas culturales "notablemente distinguidas en el proceso de configuración nacional” (4). Menciona "arquitectura, plazas, avenidas, arcos de triunfo, obeliscos, cafés, galerías, hipódromos, desfiles, carnavales, certámenes literarios, prensa, óperas, obras de ingeniería, acueductos, mataderos, trenes, alumbrado público” (4). La conjunción de elementos y el desenmascaramiento de significaciones de los signos originales en el trabajo del grupo entra en consonancia con aquellos encuentros y desencuentros que Ángel Rama describe entre "la ciudad real y la ciudad letrada" (36-37). En iGaitanista! la canción "Esto no es Madrid” crea una confluencia de aquellos espacios que la ciudad letrada bautizó imitando nombres madrileños, con espacios bogotanos donde los nombres que buscaban hidalguía y abolengo ya no tienen ninguna correspondencia con su referente original español. La canción grita a cuatro vientos cómo en Bogotá "la Plaza España es un montallantas”; "la Castellana no es paseo sino un barrio sin jaleo”; "la Gran Vía es un local, un rancho de licores” e "Iberia un expendio de carnes”. Esas "nuevas” versiones de los “viejos” topónimos en sus tierras de origen como las llama Anderson (187) ya no son lugares geográficos que retienen la tradición sino que son desvirtuadas por el consumo y el agotamiento de los significantes.

El mismo procedimiento frente a la configuración de lo nacional opera en Col \& Co: Catálogo Oficial de la Manguala, un museo en forma de libro que Arias y Troller publicaron en 1998, parodiando y recomponiendo dicho patrimonio histórico y cultural. Abarcando desde la figura de Simón Bolívar hasta el entonces presidente Andrés Pastrana, esta nueva distribución del museo apela al fútbol, el toreo, los reinados de belleza, la imitación de documentos y muchos otros recursos para crear una colección satírica de la nación. El atiborramiento de las partes en las imágenes del libro es mediatizado por parodias al turismo, la publicidad y el espectáculo para presentar una versión grotesca del patrimonio cultural e histórico pero que exhibe, salvaguardadas en el humor, aquellas prácticas discursivas que circulan entre el sujeto común y desvirtúan las versiones oficiales de los hechos, posibilitando esa fractura entre la temporalidad acumulativa y continuista de lo pedagógico y la estrategia recurrente y repetitiva de lo performativo que, para Bhabha, posibilita que ese proceso de ruptura se convierta en esa ambivalencia conceptual de la sociedad moderna, sitio de la escritura de la nación (297).

Aunque son muchos los ejemplos de producción cultural que incorporan la iconografía nacional en términos afines a los hasta aquí discutidos, cerraré esta discusión con algunos comentarios sobre Bolívar soy yo (2001), una película de Jorge Alí Triana que, por medio ${ }^{13}$ La cita de García Canclini funciona aquí, aunque en su discusión él se refiere específicamente al
videoclip publicitario de la Copa Mundo en México de 1986. 
de la tragicomedia, trae a colación la figura de Simón Bolívar. En esta producción, Santiago Miranda, el personaje principal de una telenovela que pretende mostrar una visión "más humana” del Libertador, enloquece de forma quijotesca al confundir la realidad con la ficción. Así, Miranda/ Bolívar decide reinstaurar el sueño bolivariano y salir a rectificar la historia en una nación afectada por la guerrilla, los paramilitares, un estado percibido como corrupto, arrogante e ineficaz y la delincuencia común. Con un guión bastante imbricado, Bolívar soy yo establece una crítica a la dictadura del rating y a la mediatización de la realidad por medio de las telenovelas: los amores de Bolívar cobran más peso e incluso el final que se propone -detonador del clímax de la locura de Miranda- es un fusilamiento porque favorecería mantener la teleaudiencia. Pero la crítica es de doble filo porque viene a puntualizar lo que Martín-Barbero resume como un desconocimiento del sector intelectual en Colombia sobre "la significación cultural de la televisión en el proceso de formación de una cultura nacional moderna” (“Televisión...” 432). Antagónicamente, el germen de esta película se encuentra en la serie de televisión Revivamos nuestra historia que el mismo Triana dirigiera en el pasado en un intento de "repasar" televisivamente la historia nacional.

Toda la confusión que se genera alrededor de la figura Miranda/Bolívar está a su vez mediatizada por el moldeamiento de la imagen, capacidad de representar y emitir opiniones que puede lograr la televisión. De esto último participan indiscriminadamente la madre de Miranda, los vecinos de Miranda, escolares que siguen la telenovela e incluso el presidente de la nación y su gabinete que, en un afán populista, toman prestado al personaje de la telenovela para encabezar actos oficiales como desfiles militares y encuentros de presidentes de países bolivarianos. No se quedan por fuera el ciudadano común y el grupo guerrillero que aprovecha la locura de Miranda y la coyuntura del momento para "unirse a la campaña del Libertador” (la inclusión del grupo guerrillero es un guiño indirecto al robo de la espada de Bolívar por el antiguo grupo guerrillero M-19). La farsa generada por la frágil línea que divide la realidad de la ficción funciona en Bolívar soy yo como un juego de espejos que pone en boca de un Libertador "levantado de su tumba" observaciones sobre el estado actual tanto de Colombia como de las otras naciones bolivarianas.

Este Bolívar que ya no es épico sino novelesco aproxima su conflicto personal al de la comunidad a la que pertenece. El mito desaparece y en el lugar de la epopeya del pasado habrá de localizarse lo cotidiano del presente. Esta reexaminación del padre de la Patria rompe los protocolos de la "lógica del espectáculo” y del “discurso conmemorativo" que para González-Stephan acompañaba las celebraciones del natalicio del Libertador (15). En Bolívar soy yo, la imagen de Santiago Miranda vestido de Bolívar ofreciendo una corona a su misma estatua, y conversando con ella en estado de embriaguez, rompe con esa "memoria artificial” (15). Al salirse del personaje telenovelesco, Miranda/Bolívar enfrenta la banalización de la que su nombre ha sido objeto bajo el régimen del consumo: “Seguros Bolívar”, “Expreso Bolivariano”, “Hospital Simón Bolívar” en imágenes que se intercalan con patrimonio nacional consagrado en su honor, representado en estatuas y la Plaza de Bolívar, centro arquitectónico del poder en Colombia. Bolívar ya no es el padre de la patria sino un sello de mercadeo que, en palabras del personaje de la película, no puede "satisfacer a todos sus clientes”. La superposición de imágenes hace que Miranda 
vea en quienes le rodean a los personajes que coexistieron con Bolívar: José Antonio Páez, Francisco de Paula Santander y Antonio José de Sucre, ofreciendo una excusa para traer el texto histórico y los discursos del Libertador a una nación donde, al alegar adhesión a los postulados de libertad, independencia, justicia y fraternidad, todos los sectores en disensión abusan del término bolivariano para sus causas pero desconocen el contenido y aplicabilidad de sus palabras. En una nación que se ha acostumbrado a pensar en la violencia como algo atávico y que presenta severas lesiones en la memoria histórica, no es extraño que Bolívar soy yo nos recuerde que el actor de barrios populares (Miranda) sepa más de la historia del país que el piloto que seguramente ha tenido más oportunidades inclusivas de estudio; que el nuevo Sucre sea el vigilante de la Quinta de Bolívar y que sea el único que no esté de acuerdo con la versión telenovelesca de la vida de Bolívar y que, para el presidente, los textos de Bolívar - presentados por primera vez por Miranda- suenen como propuestas de maravillosa retórica.

La sintaxis del olvido, el espacio del "mientras tanto" y la anomia de la nación, conceptos que Bhabha repasa a partir de Ernest Renan y Benedict Anderson para dilucidar sobre la cuestión de la memoria histórica (308-11) pueden concatenarse con el discurso crítico subyacente en la parte final de esta producción fílmica. Aquí, las escenas interrumpen esos estados al colar imágenes de metraje noticioso, tomadas de masacres y asesinatos en la verdadera nación atropellada, con el fin de devolver la memoria al espectador, lo cual termina siendo la meta final de Bolívar soy yo. Para esto, la película recurre a una radiografía cruda de la situación, construida con imágenes de la toma del Palacio de Justicia, de explosiones, de diferentes masacres y de asesinatos. Las imágenes de la telenovela se salen del pequeño espacio de espectacularización y sensacionalismo del televisor y se proyectan en la pantalla grande. El espectador es golpeado con ese minuto de imágenes de diferentes eventos trágicos de Colombia que lo transportan de la ficción (e ilusión) de la telenovela y el cine a la dolorosa desmesura de las múltiples formas de violencia que aquejan a Colombia: sangre, dolor, desplazamiento, abandono, muerte e impotencia desfilan en breve para romper definitivamente la parte lúdica de la trama y situar al espectador frente a la claqueta que dice "Yo soy Bolívar", una afirmación de la entidad que, como en otros ejemplos de reconversión simbólica cultural del Libertador, ya no puede connotar y continuar los mismos propósitos de construcción de la identidad nacional y de progreso que enarbolaron el icono de Simón Bolívar, posterior a la Independencia. Tal como lo discute Christopher Conway, muchas de esas representaciones tanto literarias como visuales ponen de presente las fallas del proceso de modernidad en América Latina, teniendo como objeto las promesas vacías de la ideología triunfalista que cobró forma después de la muerte de Bolívar (2-17).

Junto al desvanecimiento del sueño bolivariano elaborado a lo largo de Bolívar soy yo, estas últimas imágenes remiten a (y resumen) los aspectos de la narrativa nacional en que todas estas producciones han insistido. Son fragmentos de una nación rota, "retazos, parches, harapos y fisuras" como los denomina Bhabha, que no pueden ser ignorados para una doble escritura de la nación en la que se agotan los significantes del amarillo, azul y rojo. Las esferas de representación de lo nacional que recogen estas canciones, estos nuevos museos, estas imágenes ya no están obsesionadas con el discurso del nacionalismo ni la 
preservación del carácter esencialista de la comunidad imaginada. Apuntan, como también Bhabha propone, a la construcción de la nacionalidad como una forma de afiliación textual y social donde la localidad de la cultura se sitúa alrededor de la temporalidad, desafiando el discurso del nacionalismo (292-93). Esto no dista de la insistencia de críticos como Martín-Barbero de pensar la nación desde otros anclajes, "redes, flujos, movilidades" (“Políticas culturales" 11).

Ubicados en las contradicciones de la disyunción global, estos productos culturales y su hibridación son reiterativos de la necesidad de desmovilizar el concepto unívoco de "cultura nacional” y de pensar la nación no desde lo homogéneo sino desde su diversidad. Martín-Barbero ha criticado insistentemente la obsesión del sujeto nacional con "la buena imagen del país”, preocupación que se ha extendido (y viciado) diversas discusiones y debates críticos sobre Colombia y que relativamente traduce la ceguera de ciertos sectores para entender la liminidad cultural del país. Los diversos ejemplos hasta aquí discutidos recuerdan la percepción del sujeto de la nación como una entidad escindida "marcada internamente por la diferencia cultural y las historias heterogéneas de sectores en disensión, autoridades antagónicas y tensas locaciones culturales”(Bhabha 299), soslayando la imperiosa necesidad de entender las transformaciones culturales despojándolas de la insistencia del muestrario turístico que nos hace confundir la producción cultural como un territorio exclusivo para "mejorar la imagen en el extranjero"; "vestir de gala nuestro folclor" y "mostrar algo más que la violencia colombiana". A cambio, queda abierta la propuesta de también entender la "cultura nacional” como un espacio de reflexión y reconstrucción a partir del reconocimiento de nuestras llagas.

\section{BiBLIOGRAFÍA}

Anderson, Benedict. Imagined Communities: Reflections in the Origins and Spread of Nationalism. Londres: Verso, 1983.

Arias, Eduardo y Karl Troller. Col \& Co: Catálogo Oficial de la Manguala. Bogotá: Planeta, 1998.

Aterciopelados. <http://www.aterciopelados.com> El Dorado. Culebra/BMG, 1995.

Evolución. BMG/Ariola, 2002. La pipa de la paz. Ariola, 1996.

Baena, Rafael. “El escudo de la discordia”. Revista Credencial (julio 2004): 22-28.

Bejarano, Ana María. “The Constitution of 1991: An Institutional Evaluation Seven Years Later”. Violence in Colombia 1990-2000: Waging War and Negotiating Peace. Charles Berquist, Ricardo Peñaranda y Gonzalo Sánchez, eds. Delaware: SR Books, 2001. 53-74.

Bhabha, Homi K. "DissemiNation: Time, Narrative, and the Margins of the Modern Nation". Nation and Narration. Homi Bhabha, ed. Londres: Routledge, 1990. 291-322.

Bolívar, Ingrid. "Interpretaciones sobre La Violencia en la segunda mitad del siglo XX”. Conferencia en el Museo Nacional. Bogotá, 17 de mayo de 2004. 
Bolívar soy yo. Dir. Jorge Alí Triana. Actores Robinson Díaz y Amparo Grisales. Grupo Colombia y United Angel Productions, 2002.

Braun, Herbert. “Cóndores de ayer y hoy: de cómo recuperar La Violencia colombiana”. Revista de Estudios Colombianos 23-4 (2002): 15-23.

"Colombia: entre el recuerdo y el olvido: Aves de corral, toallas, whisky... y algo más”. Número 40 (marzo-mayo 2004): i-xvi.

Chaparro Valderrama, Hugo. “La rockoteca del Divino Niño”. Gaceta 47 (2000): 106-10.

Conway, Christopher. The Cult of Bolivar in Latin American Literature. Gainesville: Florida UP, 2003.

Echeverri, Andrea. "Hacer rock en Colombia”. Gaceta 47 (2000): 119.

El Ocio $<$ http://www.elocio.com>

García Canclini, Néstor. Culturas híbridas: estrategias para entrar y salir de la modernidad. México: Grijalbo, 1989.

González Stephan, Beatriz. “Coleccionary exhibir: la construcción de patrimonios culturales”. Hispamérica 29 (2000): 3-17.

Hall, Stuart. “Culture, Identity and Diaspora”. Identity, Community, Culture, Difference. J. Rutherford, ed. Londres: Lawrence \& Wishart, 1990. 222-37.

Jaramillo Vélez, Rubén. Colombia: la modernidad postergada. Bogotá: Argumentos, 1998.

Martín-Barbero, Jesús. “Televisión y literatura nacional”. Narrativa colombiana del siglo XX: hibridez y alteridades. María Mercedes Jaramillo, Betty Osorio y Ángela I. Robledo, eds. Bogotá: Ministerio de Cultura, 2000. 431-61.

"Políticas culturales de nación en tiempos de la globalización”. Gaceta 48 (enero 2001- diciembre 2002): 3-18.

“¡Oh júbilo inmortal! Cambio (5 de julio de 2004): 56-58.

Orquesta Sinfónica de Chapinero y Hotel Regina. ¡Gaitanista! MTM-Talento. 1996.

Ospina, William. ¿Dónde está la franja amarilla? Bogotá: Grupo Editorial Norma, 1997.

Pécaut, Daniel. Guerra contra la sociedad. Bogotá: Espasa, 2001.

Posada Carbó, Eduardo. ¿Guerra civil? El lenguaje del conflicto armado en Colombia. Bogotá: Ediciones Alfaomega, 2001.

Rojas, Cristina. Civilization and Violence: Regimes of Representation in Nineteenth Century Colombia. Minneapolis: U of Minnesota P, 2002.

VV.AA.: Arte y violencia en Colombia desde 1948. Bogotá: Museo de Arte Moderno/ Editorial Norma, 1999. 